purpose of such institutions is to work jointly on issues and concerns of common interest in a more integrated fashion providing a multilateral, multicultural platform for both students and faculty of the neighboring countries.

\section{Concluding Observations}

Both the number and the dimensions of international collaborations have increased, with India adopting a more open approach after the I990s. However, in the newfound frenzy to internationalize higher education and the "brand status" attached to a foreign degree in Indian society, a number of substandard (even unaccredited) foreign universities have already found their way onto Indian soil. Strict monitoring and governance, with strategic government intervention to provide clear directions and measurable deliverables for all these collaborative ventures, is a must. India's desire to emerge as an equal partner is subject to quality parameters. Decreasing quality of higher education in India is likely to

\section{A shift from research and training to teaching will allow for global exposure to a larger student community but with private institutions leading the race it is likely to remain restricted to an elite few.}

act as a major deterrent for top brand universities and institutions to collaborate with India. Domestically, as well, the quality gap across a range of higher education providers may lead to further polarization, as only good and highly ranked institutions would be able to reap the benefits of internationalization. This can have long-term implications of societal divide arising out of "global academic impoverishment."

The visible intentions of fast tracking India's internationalization process now require a clear-cut policy direction. With the much-debated 2010 Foreign Education Institutions (Regulation of Entry and Operations) Bill still waiting to see the light of the day, coupled with changes in the ministry, ambiguity clouds the future. However, one thing is for sure: there is no looking back, but only making the best of newfound opportunities, as both domestic needs and aspirations are high. Strategizing internationalization at three levels - global, national, and institutional-backed by a rigorous competency-building drive to translate it into practice, can go a long way in taking this march forward.

\section{Internationalizing Research in Saudi Arabia: Purchasing Questionable Privilege}

\author{
Manail Anis Ahmed
}

Manail Anis Ahmed is a higher education management professional. She currently serves as Senior Grants Specialist at the Research \& Consultancy Institute at Effat University, a private university for women in Jeddah, Saudi Arabia. E-mail: manailahmed@gmail.com.

A s part of its ambition to create a "knowledge economy" Aand ultimately diversify revenue sources, Saudi Arabia has been working aggressively to boost research production. The Kingdom is young and its university and higher education system even more so. Focusing initially on building schools and later tertiary teaching facilities, it was not able to establish scholarly research production until very recently. However, research activity has been given a massive push over the past few years. The country has made great strides in this regard with the building of many higher education institutions and research facilities.

\section{The Role of Ran King}

Accompanying the race toward the creation of new universities and other educational institutions has been the pursuit of quality. Whereas robust national systems of quality assurance (such as the National Commission for Academic Accreditation and Assessment) have come into existence, there is also a need to benchmark against more global and publicly visible systems. As global university rankings have gained widespread acceptance and become the dominant form of consumer-oriented information producers, Saudi universities have been preoccupied lately with being featured in these lists.

In the report- “Global University Rankings and Their Impact” by Andrejs Rauhvargers-commissioned by the European University Association in 20II, it says: "One problem or 'unwanted consequence,' as rankers sometimes call the negative impacts of rankings, is that both society and policy makers are tempted to judge all higher education in the world by the standards that rankings use to detect the top research universities, rather than applying one of the core principles of quality assurance-the "fitness for purpose' principle." And he continues: “Thus, one 'unwanted consequence' of global league tables is that higher education institutions with other missions than that of being top research universities may have to re-justify their profile at a time when mission differentiation is at the top of higher education agendas across Europe." 


\section{Generous Financial Incentives at the Expense of the LOCAL RESEARCH ENTERPRISE}

This problem becomes immediately apparent in the case of Saudi universities. Whereas the first university in the country was established as late as I957; and whereas there is a huge and pressing need to educate a fast-growing population of youth to effectively enter the workforce and become productive members of society, there is also a pressure on the country's institutions to produce publishable research output in English that can be leveraged for the various different international university ranking systems.

\section{Perhaps what would be best advised would be a more comprehensive in- ternationalization of research at Saudi universities, placing more value on lo- cal knowledge and indigenous methods of knowledge production and transmis- sion.}

\section{Benefits, Risks, And Controversies}

In such a situation, a default internationalization of research has come about, perhaps a faster internationalization than was possible, or even desirable, in the development of the rest of the Saudi academy. This internationalization has reaped huge rewards with regard to boosting the country's research production. In fact, three Saudi public universities have been featured in various international rankings over the past decade-and others, large and small, are making their way there now.

An interesting aspect of this research-based internationalization is that it has so far been focused in the areas of the life, natural, information and engineering sciences - the humanities are nowhere to be seen, and the social sciences are few and far behind. But the most problematic aspect of this internationalization is that institutions, both large and small, are allocating — and paying out-substantial proportions of their research budget to invite highly cited international researchers to publish with the paying institution listed as the researcher's secondary affiliation. This practice was highlighted in a controversial article in Science Magazine in December 20II and has since been widely debated in both local and global fora as being problematic. The contracts offered to these "visiting researchers," "research fellows," or "international partners" generally require a minimum number of publications per each contract period, and only a nominal requirement of physical presence at the host institution.

\section{The Price of "Academic Capitalism"}

Whereas some academics deride the practice of paying others to make it seems like one's own institution did the work, others think of it as merely another aspect of capitalismbeing able to buy the best global talent by paying top dollar for it and in the process deriving credit for research production. The practice of hiring prolific, highly cited international researchers in order to boost the research reputation of any given institution remains a contested one. However, this debate does bring into focus the problems associated with the urgent internationalization of research in a country like Saudi Arabia.

The more widely accepted desirable outcomes of higher education internationalization-i.e., the exchange of people, knowledge, ideas, and research production systems across boundaries-have in this case been supplemented by a too-easy prepared solution with regard to research production and development. It is one thing to invite foreign scholars and researchers to help build an indigenous, vibrant, and sustainable research culture that can eventually thrive independently of any outside help. It is entirely different to supplant local research production and to coopt foreign resources that have little vested in the research development of the host institution or country beyond coauthorship. Thus, the internationalization of research in Saudi Arabia is not devoid of controversy.

\section{A Middle WaY}

Perhaps what would be better to advise a more gradual, comprehensive internationalization of both teaching and research at Saudi universities. This would involve an openness toward traditional models of research production (such as the documentation of oral histories and the acknowledgement of verifiable "chain-based" historic research resources) and the placing of more value on local knowledge and indigenous methods of knowledge production and transmission. The kingdom could also benefit far more from diverting resources to support research produced locally: by providing rigorous training in international research methods, sponsoring the translation of Arabic research output into English, and in the process educating Saudi researchers about the importance of peer review, academic influence through citation, and ultimately the production of high-quality research to an international standard.

By doing the above, Saudi Arabia would be able to build a gradual and robust local research culture, creating a valid space for research production that acknowledges differences in international research methods, while incorporating best practices from academia worldwide. Given strong state 
support, and keeping in mind the potential inherent in the country's nascent research enterprise, a research culture of its own is surely not too far in the Saudi future.

\section{New Directions for Interna- tionalization of Tertiary Edu- cation in Latin America and the Caribbean}

\section{Jocelyne GaCel-Ávila}

Jocelyne Gacel-Ávila is a Researcher of the Mexican National Research System, Professor of the Doctoral Program on higher education, Associate Dean for Social Sciences and Humanities at the University of Guadalajara, and currently President of AMPEI, Mexico. E-mail: jgacelav@ gmail.com.

or Latin America and the Caribbean, like other regions,
internationalization is a key strategy for the transformation and improvement of tertiary education, in terms of educating graduates with the cognitive and intercultural skills needed by an increasingly globally connected society and economy. The key question is if internationalization is actually being used to help the region make the transformations of tertiary education needs. The main findings of the 20I4 Global Internationalization Survey, carried out by the International Association of Universities (IAU) in 20I4, give some indications.

\section{Balance, Progress and Challenges}

The IAU survey shows some interesting new trends in Latin America and the Caribbean. In particular on external drivers for internationalization, government policies were ranked first ahead of business and industry demand, in tune with global findings. This stands in opposition to the 2010 survey, where the latter was ranked first, and reflects how weak government support was perceived at that time, as collaboration between industry and spending on tertiary education is notably low in the region. An increase in governmental support and funding has also been reported, showing a change in trends, as in the 2010 survey of Latin American and the Caribbean government funding turned out to be the lowest in the world. Both developments are definitely positive and confirm an increasing public inter- est to foster tertiary education internationalization. Another new element-mainly due to the development of national and regional rankings - is that international rankings are acknowledged as among the top three drivers, of internationalization in Latin American and the Caribbean. In the past, the region traditionally ignored this phenomenon.

That part of the world is the only region reporting increased international networking by faculty/researchers as the main benefit of internationalization. This confirms earlier findings, as in the 2005 World Bank study on higher education internationalization, which that academic community still feels rather disconnected from the rest of the world.

At the institutional level, participating institutions consider their main risk to be that international opportunities are accessible only to students with financial resources, followed by difficulty in regulating locally the quality of foreign program offerings. For society, the main risk perceived is unequal sharing of benefits of internationalization and growing gaps among higher education institutions within countries. Both responses suggest internationalization is perceived

\section{Although priorities seem to shift over the years, the results express a concern about the potential disconnect between the role of higher education as a public good and as a tradable commodity.}

as a factor of increased inequity among individuals and institutions within a region already showing high levels of concern for these matters. A further concern is expressed toward foreign providers, which are on the rise in the region because of insufficient access provided by the public sector. In 20I0, brain drain was ranked as the principal risk, while in 2005 the loss of cultural identity was reported as the main threat. Although priorities seem to shift over the years, these results express a concern about the potential disconnect between the role of higher education as a public good and as a tradable commodity.

As far as internal and external obstacles to internationalization are concerned, the language barrier is ranked higher than in other regions, a fact which coincides with the reality of low levels of foreign-language skills among students and the population overall in the region.

Regarding regional priorities for partnerships, Europe and North America are ranked first on an equal footing, Latin American and the Caribbean itself second and Asia 